\title{
Use of Counter and rocket immunoelectrophoresis in acute respiratory infections due to Streptococcus pneumoniae
}

\author{
R. C. SPENCER AND M. A. SAVAGE
}

From the Department of Bacteriology, Wright Fleming Institute, St. Mary's Hospital Medical School, Paddington, London W2

SYNOPSIS The use of Counter immunoelectrophoresis (CIE) for the detection of pneumococcal capsular antigen in the sputum and serum of patients suffering from acute respiratory infections is described. The CIE of sputum gave positive results in $224(99 \%)$ out of 225 samples in which Streptococcus pneumoniae was isolated by cultural techniques, and in $23(9 \%)$ out of 262 samples in which no or other potential pathogens had been isolated. In the detection of capsular antigen in serum, CIE was positive in $32(35 \%)$ out of 92 pneumonia cases and was associated with an increase in mortality.

In the clinical management of pneumonia where the patient receives antimicrobial therapy before the causal organism has been identified, a specific bacteriological diagnosis is frequently rendered impossible because of the growth of such replacement organisms as Escherichia coli and Klebsiella species (Spencer and Philp, 1973). Since the detection of antibodies or polysaccharide capsular antigens might be of value in this situation, the use of Electrosynerese (Bussard, 1959), a development from the technique of Lang and Haas (1957), or Counter immunoelectrophoresis (CIE), as it is more commonly termed, has been investigated. The present report is primarily concerned with the diagnostic and prognostic use of this technique in pneumonia due to Streptococcus pneumoniae.

\section{Patients and Methods}

\section{PATIENTS}

A group of 225 consecutive patients, in whom Str. pneumoniae had been isolated from the sputum as the potential pathogen, was balanced with a control group of 262 patients from whom another or no potential pathogen had been isolated. The first group was subdivided into three categories: (1) patients with clinical pneumonia confirmed by chest $x$-rays, (2) patients with exacerbations of chronic lung diseases, eg, bronchitis, asthma, and

Received for publication 6 August 1975 bronchiectasis, and (3) surgical postoperative patients who had developed a productive cough but did not fall into the previous two categories.

\section{SAMPLES}

Sputum and serum were collected from the patients as soon as the clinical diagnosis had been made. The sputa were cultured on blood agar under carbon dioxide at $37^{\circ} \mathrm{C}$. These were read after overnight incubation, and potential pathogens were identified by standard methods (Cowan and Steel, 1974). Very small numbers of potential pathogens found only in the inoculation well were not regarded as significant.

\section{IMMUNOELECTROPHORESIS}

Counter Immunoelectrophoresis (CIE)

This was performed with a method based on that of Dorff et al (1971). The stock buffer used was barbitone/sodium barbitone, $\mathrm{pH} 8 \cdot 2$, and microscope slides were covered with $0.9 \%$ agarose (Miles-Seravac Ltd, Maidenhead, Berks) in halfstrength buffer sufficient to give a depth of $1 \mathrm{~mm}$ of agarose. Ten $\mu$ l amounts of antibody or test fluid were employed and a constant voltage of $20 \mathrm{~V}$ per $\mathrm{cm}$ was applied for one hour at room temperature. After electrophoresis the gel was washed in $5 \%$ sodium citrate for 15 minutes and examined by reflected light for lines of precipitation. Gels were then dried and stained for record purposes. 


\section{Rocket Immunoelectrophoresis}

Pneumococcal Omniserum (Statens Serum Institut, Copenhagen) was diluted to 1 in 50 with $0.9 \%$ agarose in barbitone buffer, $\mathrm{pH} 8.6$, and $5 \mathrm{ml}$ was pipetted onto a $7 \mathrm{~cm}$ square glass plate. Wells, 3 $\mathrm{mm}$ in diameter with an edge to edge separation of not less than $3 \mathrm{~mm}$, were cut along a line $1 \mathrm{~cm}$ from the edge of the slide. A $10 \mu \mathrm{l}$ sample of sputum or serum was added to the appropriate well and a constant voltage of $10 \mathrm{~V}$ per $\mathrm{cm}$ was applied for 3 hours. Following this, the gels were washed in $5 \%$ sodium citrate for 30 minutes and then in two changes of saline over 18 to 20 hours. Finally, the gels were dried and stained in Coomassie blue. The height of the precipitin peak was measured and the amount of capsular antigen was determined from a standard graph.

\section{PREPARATION OF ANTIGENS}

Equal volumes of sputum and buffered pancreatin, $\mathrm{pH} 7.5$, were incubated at $37^{\circ} \mathrm{C}$ for 30 minutes on a Matburn blood cell suspension mixer and centrifuged, and the supernatant was decanted for use. Serum samples were tested both undiluted and at a dilution of $1: 10$. To test for cross reactions with the capsular antigens of other organisms isolated in sputum, extracts of Haemophilus influenzae, Escherichia coli, Proteus mirabilis, Klebsiella aerogenes, Pseudomonas aeruginosa, Staphylococcus aureus, Streptococcus viridans, and Candida albicans in saline were prepared. No cross reactions were found. Pneumococcal polysaccharide capsular antigen was prepared by culturing three strains of Str. pneumoniae types 3,6 , and 14 in glucose broth for 48 hours. Two volumes of cold $95 \%$ ethyl alcohol were added, and the mixture was left at $4{ }^{\circ} \mathrm{C}$ overnight and then centrifuged. The deposit was freezedried for preparation of known amounts of standards. This standard antigen was used to determine the least amount of capsular antigen reacting in the CIE and the actual amount of capsular antigen using rocket immunoelectrophoresis.

PNEUMOCOCCAL TYPING

Fifty-four isolates of Str. pneumoniae were serotyped by Dr M. T. Parker, Central Public Health Laboratory, Colindale.

\section{Results}

For the patients from whom Str. pneumoniae had been isolated as the probable pathogen, the correlation between routine culture methods and the detection of polysaccharide capsular antigen in the sputum is given in table $I$. The pneumococcus isolated from one patient was of a type not included

\begin{tabular}{lll}
\hline Category & No. & CIE Positive \\
\hline Pneumonia & 92 & 91 \\
Exacerbations of chronic chest & 83 & 83 \\
disease & 51 & 51 \\
Postoperative & & \\
\hline
\end{tabular}

Table I Pneumococcal antigen in culture positive sputum

in the preparation of the Omniserum; extracts of a $\overrightarrow{\mid}$ pure culture did not produce a precipitin line with CIE nor did they react when layered on Omniserum 웅 in a tube. In the control patients from whom no Str. pneumoniae had been cultured, $23(9 \%)$ of the 0 262 samples examined were shown to contain the capsular antigen of Str. pneumoniae (table II). $\stackrel{\infty}{y}$

\begin{tabular}{|c|c|c|}
\hline Potential Pathogen & Sputum Cultures & CIE Positive \\
\hline H. influenzae & 25 & 0 \\
\hline Enterobacteriaceae & 40 & $3^{1}$ \\
\hline Staph. aureus & 5 & 0 \\
\hline C. albicans & 3 & 0 \\
\hline Normal regional flora & 189 & $20^{1}$ \\
\hline
\end{tabular}

Table II Pneumococcal antigen in culture negative sputum

${ }^{1}$ All these patients had received prior antimicrobial therapy.

In the serum of paients with proven pneumonia (category 1) CIE detected capsular antigen in $32(35 \%)$ of the 92 cases (table III). Antigen was also detected in one patient with a chronic chest票 disease (category 2) but in none of the postoperative patients of category 3 (table III).

\begin{tabular}{|c|c|c|}
\hline Category & Antigen Positive & Antigen Negative \\
\hline 1 & 32 & 60 \\
\hline 2 & 1 & 82 \\
\hline 3 & 0 & 51 \\
\hline
\end{tabular}

The least amount of capsular antigen reacting in the CIE when doubling dilutions of standard antigem were used was found to be $0 \cdot 3 \mu \mathrm{g}$ per ml of sample ${ }_{\sigma}^{\omega}$ In the rocket immunoelectrophoresis no significant difference was observed between the antigen con $\frac{0}{D}$ centrations encountered in the sputum of the threes categories of patients studied (table IV). In the pneumonia cases, category 1 , no correlation was. found between the quantity of capsular antigen ind serum and the patient's prognosis; amounts range ${ }_{0}$ from 0.35 to $2 \cdot 1 \mu \mathrm{g} / \mathrm{ml}$ (mean $1 \cdot 1 \mu \mathrm{g} / \mathrm{ml}$ ). Capsula? antigen persisted in the serum from 2 to 14 days witk a mode of 8 and a mean of 7 days. 


\begin{tabular}{lccc}
\hline & Category 1 & Category 2 & Category 3 \\
\hline Range & $0.35-2 \cdot 1$ & $0.3-1.3$ & $0.3-1.5$ \\
Mean & 0.85 & 0.80 & 0.82 \\
\hline
\end{tabular}

Table IV Amount of capsular antigen in sputum $(\mu g / m l)$

\section{PROGNOSTIC VALUE}

The 32 cases from category 1 who had positive circulating capsular antigen had a worse prognosis than the 60 negative ones. The death rate from pneumonia was $50 \%$ in the CIE positive cases compared with only $10 \%$ in the CIE negative group. Patients with circulating capsular antigen also had a longer stay in hospital, a mean of 16 days compared with eight for those without detectable antigen. The incidence of jaundice was increased, occurring in $15 \%$ of patients against only $2 \%$ in patients without serum antigen.

\section{SEROTYPES OF STR. PNEUMONIAE}

The serotypes of 54 consecutive isolates of Str. pneumoniae and their relation to the three clinical categories are shown in table V.

\begin{tabular}{|c|c|c|c|c|c|}
\hline \multirow[t]{3}{*}{ Pneumococcal Serotype } & \multicolumn{4}{|c|}{ Categories } & \multirow[t]{3}{*}{ Total } \\
\hline & \multicolumn{2}{|l|}{1} & \multirow[t]{2}{*}{2} & \multirow[t]{2}{*}{3} & \\
\hline & $\begin{array}{l}\text { Serum } \\
\text { CIE+ }\end{array}$ & $\begin{array}{l}\text { Serum } \\
\text { CIE- }\end{array}$ & & & \\
\hline 1 & 0 & 0 & 1 & 0 & 1 \\
\hline 3 & 4 & 3 & $1^{1}$ & 2 & 10 \\
\hline 6 & 0 & 0 & 1 & 1 & 2 \\
\hline 8 & 0 & 1 & 0 & 0 & 1 \\
\hline 9 & 0 & 1 & 3 & 4 & 8 \\
\hline 11 & 0 & 0 & 1 & 1 & 2 \\
\hline 12 & 0 & 0 & 1 & 0 & 1 \\
\hline 14 & 2 & 1 & 4 & 0 & 7 \\
\hline 17 & 0 & 2 & 1 & 2 & 5 \\
\hline 18 & 0 & 0 & 1 & 0 & 1 \\
\hline 19 & 0 & 1 & 2 & 0 & 3 \\
\hline 23 & 1 & 0 & 0 & 0 & 1 \\
\hline 28 & 0 & 1 & 0 & 0 & 1 \\
\hline 31 & 0 & 0 & 1 & 0 & 1 \\
\hline 32 & 0 & 0 & 0 & 1 & 1 \\
\hline 33 & 0 & 0 & 1 & 0 & 1 \\
\hline 34 & 2 & 4 & 0 & 0 & 6 \\
\hline 35 & $\mathbf{0}$ & 1 & 1 & 0 & 2 \\
\hline 39 & 0 & 1 & 0 & 0 & 1 \\
\hline
\end{tabular}

Table V Correlation of pneumococcal types and clinical categories

${ }^{1} \mathrm{CIE}+$ antigen in serum

\section{Discussion}

The determination of the cause of acute bacterial pneumonia remains a problem, prior antimicrobial therapy being a common reason for failure (Spencer and Philp, 1973). Blood culture is the most useful cultural method of confirming the clinical diagnosis but is positive in only $20-30 \%$ of cases (Austrian and Gold, 1964; Bath et al, 1964). The use of CIE has been recommended as a possible alternative to blood culture (Kenny et al, 1972; Lancet, 1974) with the advantage of giving results in less than 2 hours, thus avoiding the delay of 24-48 hours for a result by bacterial culture. It is also able to detect very small amounts of capsular antigen. The CIE of sputum is a most useful test, giving results equivalent to those obtained by cultural techniques and also yielding positive results in $9 \%$ of patients in whom no or other organisms had been isolated. All of these latter patients had received prior antimicrobial therapy. It has been claimed (Verhoef and Jones, 1974) that pneumococcal capsular antigen is more likely to be present in the sputum of patients suffering from pneumonia than in those with other respiratory infections. However, the results presented in table I confirm our earlier findings (Spencer and Savage, 1974) that immunoelectrophoresis fails to distinguish pneumonia from other chest infections caused by Str. pneumoniae. Moreover, applying rocket immunoelectrophoresis, a simple, quick, and reproducible method of quantitating a single antigen against its antibody (Laurell, 1966; 1972), there was no significant difference in the mean values obtained in all three categories (table IV).

Thirty-five per cent of patients suffering from pneumonia had pneumococcal capsular antigen in their serum, a figure similar to that obtained by Coonrod and Rytel (1973) and Tugwell and Greenwood (1975). It has also been reported that antigens are present in the serum of patients not suffering from pneumonia (Bartram et al, 1974). However, in our studies, in only one patient who was not suffering from pneumonia was pneumococcal capsular antigen detected in the serum. The clinical history is therefore noteworthy. He was a 58-year-old chronic bronchitic who had been admitted with haematemesis and abdominal pain. Gastroscopy revealed a gastric ulcer and a Bilroth 1 partial gastrectomy was performed. He developed a postoperative chest infection and Str. pneumoniae type 3 was isolated from the sputum. Use of CIE showed capsular antigen in the sputum but not in the serum. Nine days later his abdominal wound dehisced and needed resuturing. A wound swab was taken and Str. pneumoniae type 3 was cultured. Since serum taken at this time was positive for capsular antigen, it seems likely that this resulted from the wound infection.

It has been reported (Dochez and Avery, 1917; Blake, 1918; Bukantz et al, 1942; Coonrod and Rytel, 1973) that the presence of capsular antigen in serum is a poor prognostic sign, which the results of our studies confirm. In patients with detectable 
levels of capsular antigen in their serum there was a significantly higher death rate $(50 \%$ against $10 \%)$; prolonged pyrexia and other constitutional complications such as jaundice were more severe in these patients. The persistence of pneumococcal antigen in the serum ranged from two to 14 days with a mode of eight. The actual amount of serum capsular antigen as measured by rocket immunoelectrophoresis, however, did not seem to bear any relation to the eventual outcome of the disease. Death occurred in patients with very low serum levels while the highest level observed, $2 \cdot 1 \mu \mathrm{g} / \mathrm{ml}$, was detected in a patient two days before her discharge from hospital when she was otherwise well. Whether certain pneumococcal types were more likely to produce detectable antigen was also examined. Serotype 34 seemed to be isolated from cases of pneumonia regardless of the presence or absence of capsular antigen. The type 3 pneumococcus was not only the most frequently grown serotype but produced the antigen most commonly encountered in the serum. Infections with this serotype are associated with a high mortality, $48 \%$ (Austrian, 1968), and indeed all four patients with antigenaemia in category 1 died.

It is concluded that Counter immunoelectrophoresis of sputum in acute respiratory diseases can give evidence of pneumococcal infection in less than two hours and rapid confirmation of the clinical diagnosis. The clinical signs and chest $x$-rays remain essential to diagnosis. The detection of capsular antigen in serum is particularly valuable, indicating the patients in whom there is the greatest risk of mortality and who therefore require more careful management. Rocket immunoelectrophoresis, however, appears to be of little value in the management of these patients.

We thank Professor A. A. Glynn and Dr R. R. Davies for helpful advice and criticism in preparing this report, and Dr M. T. Parker for serotyping the pneumococcal strains.

\section{References}

Austrian, R. (1968). Current status of bacterial pneumonia with especial reference to pneumococcal infection. $J$. clin. Path., 21, Suppl. 2, 93-97.
Austrian, R. and Gold, J. (1964). Pneumococcal bacteraemia with especial reference to bacteremic pneumococcal pneumonia. Ann. intern. Med., 60, 759-776.

Bartram, C. E., Jr., Crowder, J. G., Beeler, B., and White, A. J. (1974). Diagnosis of bacterial diseases by detection of serum antigens by counterimmunoelectrophoresis, $\overline{\bar{D}}$ sensitivity, and specificity of detecting Pseudomonas and $\overrightarrow{\mathbb{D}}$ pneumococcal antigens. J. Lab. clin. Med., 83, 591-598. ¿

Bath, J. C. J. L., Boissard, G. P. B., Calder, M. A., and §ొ Moffat, M. A. J. (1964). Pneumonia in hospital practice in Edinburgh 1960-1962. Brit. J. Dis. Chest, 58, 1-16.

Blake, F. G. (1918). Antigen-antibody balance in lobar $\vec{\overrightarrow{ }}$ pneumonia. Arch. intern. Med., 21, 779-790.

Bukantz, S. C., De Gara, P. F., and Bullowa, J. G. M. (1942). Capsular polysaccharide in the blood of patients $\frac{7}{0}$ with pneumococcic pneumonia. Arch. intern. Med., 69, ㄱ 191-212.

Bussard, A. (1959). Description d'une technique combinant $\dot{\omega}$ simultanément l'électrophorèse et la précipitation im- $\vec{\infty}$ munologique dans un gel: l'électrosynérèse. Biochem. $\stackrel{\infty}{-}$ biphys. Acta (Amst.), 34, 258-260.

Coonrod, J. D. and Rytel, M. W. (1973). Detection of typespecific pneumococcal antigens by counterimmunoelectrophoresis. J. Lab. clin. Med., 81, 770-786.

Cowan, S. T. and Steel, K. J. (1974). Manual for the Identification of Medical Bacteria, 2nd edition. Cambridge $\stackrel{\bigcirc}{\supset}$

University Press, London.
Dochez, A. R. and Avery, O. T. (1917). The elaboration of $\vec{\theta}$ specific soluble substance by pneumococcus during. growth. J. exp. Med., 26, 477-493.

Dorff, G. J., Coonrod, J. D., and Rytel, M. W. (1971). Detection by immunoelectrophoresis of antigen in sera of patients with pneumococcal bacteraemia. Lancet, $1, \bar{\partial}$ 578-579.

Kenny, G. E., Wentworth, B. B., Beasley, R. P., and Foy, $\stackrel{\circ}{\mathbb{D}}$ H. M. (1972). Correlation of circulating capsular poly- $\varrho$ saccharide with bacteremia in pneumococcal pneumonia. $\overrightarrow{\vec{O}}$ Infect. Immun., 6, 431-437.

Lancet (1974). Editorial. Microbial-antigen detection. $\frac{\vec{J}}{\vec{J}}$ Lancet, 2, 138-139.

Lang, V.N. and Haas, J. (1957). Nachweis präzipitierender und nichtpräzipitierender Antikörper durch Überwanderungs Electrophorese. Int. Arch. Allergy, 10, 305-316.

Laurell, C. B. (1966). Quantitative estimation of proteins by electrophoresis in agarose gel containing antibodies. Analyt. Biochem., 15, 45-52.

Laurell, C. B. (1972). Electrophoretic and electroimmunochemical analysis of proteins. Scand. J. clin. Lab. Invest.,
29, Suppl., 124, pp. 21-23.

Spencer, R. C. and Philp, J. R. (1973). Effect of previous antimicrobial therapy on bacteriological findings in을. patients with primary pneumonia. Lancet, 2, 349-351.

Spencer, R. C. and Savage, M. A. (1974). Pneumococcalo antigen in sputum. (Letter.) Lancet, $1,988$.

Tugwell, P. and Greenwood, B. M. (1975). Pneumococcal antigen in lobar pneumonia. J. clin. Path., 28, 118-123. W

Verhoef, J. and Jones, D. M. (1974). Pneumococcal antigeng in sputum. (Letter.) Lancet, 1, 879. 
Hand Book of Haemophilia, Parts I and II. Edited by K. M. Brinkhous and H. C. Hemker. (Part I: Pp. xxv + 446; Part II: ix + 447-927; illustrated; D.fl. 325,00; US \$135.50.) Amsterdam: Excerpta Medica. 1975.

I must begin my review by saying that this book is beautifully produced and a delight to hold and look at. The book comes in two volumes and contains 63 chapters written by 89 authors. The chapters are grouped into sections, each section dealing with a particular aspect of haemophilia. In volume I, Section $A$, comprising four chapters, deals with the general aspects of haemophilia and Christmas disease. Section $B$ considers, among other things, the biochemistry of factors VIII and IX, the mode of inheritance of haemophilia and Christmas disease, and the methods for detecting the different variants of those factors. Section $\mathrm{C}$ deals with the clinical and pathological aspects of haemophilia. Volume II is laid out in the same way and has sections dealing with replacement therapy, management of patients with antibodies to factor VIII, general management, and dental management, and it ends with a discussion of the educational and socioeconomic problems of haemophilia.

Most of the chapters are of a high standard and provide a useful and wide ranging review of the present state of knowledge of many aspects of haemophilia, but some are much more limited in their scope and present a more personal and often not generally accepted point of view. There is a good deal of repetition throughout the book, and this is probably unavoidable in a multi-author work of this kind. Nevertheless, I think repetition might have been minimized had different groups of authors not been asked to write on similar subjects. For example, the chapter on 'Current approaches to the characterization of factor VIII' is followed by a chapter on the 'Biochemistry of factor VIII'. The ground covered by both chapters is much the same. There is considerable overlap between several other chapters. At the end of each chapter there is a useful list of references, many of which are to articles published as recently as 1974 . The illustrations are of a high standard, and this applies particularly to the radiographs of joints which are well reproduced and clearly demonstrate the different lesions discussed.

This book is a valuable addition to the literature on haemophilia and should be on the shelf of every department concerned with research into haemophilia or with clinical management. At $\mathbf{6 6 5}$, however, the book is very expensive, even by today's standards.

C. R. RIZZA

\section{Correction}

Use of Counter and rocket immunoelectrophoresis in acute respiratory infections due to Streptococcus pneumoniae by R. C. Spencer and M. A. Savage (J. clin. Path., 1976, 29, 187-190)

On page 188 the first sentence of the last paragraph of the right-hand column should read:

The least amount of capsular antigen reacting in the CIE when doubling dilutions of standard antigen were used was found to be $0.03 \mu \mathrm{g}$ per $\mathrm{ml}$ of sample. 